\title{
Women in science and engineering
}

from Richard Pearson

\section{One of the biggest changes in the employment scene in the second half of this century has been the rising participation of women in the labour market.}

IN the 1930s only one in ten women of working age in the United Kingdom were in employment, now nearly half are in or seeking employment; and women now account for 43 per cent of the labour force.

To date, however, women have been concentrated in the unskilled, lower-paid jobs, often working part-time hours. In terms of paper qualification, far fewer women are qualified than men. The 1981 Census of Population shows that while 7 per cent of adult men were graduates, the proportion of women so qualified was less than half this figure, at 3 per cent. However, the proportion of women gaining degrees has been rising fast towards equality, so that in 198342 per cent of those in higher education in 1983 were women compared with under 30 per cent twenty years earlier. Although more women are becoming qualified, the range of qualifications they are gaining is still markedly different from their male counterparts.

One of the most critical points for career choice is in the school system, where, by the age of 13 , most girls have committed themselves to arts rather than science subjects, which severely constrains their later entry into science-based careers and courses in higher education. In terms of school qualifications, the proportion of girls gaining two or more A level qualifications in science, the usual minimum entry qualification for science or engineering courses in higher education, has barely changed, averaging about one in five.

Thus although the proportion of women going into higher education has risen dramatically over recent years, and they now account for more than half the intake into many medical schools, the changes on science and engineering courses have been far less marked. While in the case of engineering the proportion has more than doubled, women still account for only one in ten students, and the proportion of women on science courses has risen only slightly (Table 1). Of the women graduating

Table 1 Women first-year students as $\%$ of all students

\begin{tabular}{lr} 
Medicine & 49.0 \\
Engineering and technology & 9.5 \\
Science & 33.1 \\
Social science & 44.4 \\
Language, literature & 69.0 \\
Other arts & 54.6 \\
All subjects & 40.7 \\
\hline
\end{tabular}

Source: UCCA figures for 1982. last year, nearly two-thirds had art or social science degrees, only 21 per cent had science degrees and a mere 4 per cent had engineering degrees.

Curiously, girls' preferences within engineering do not seem to conform to the expected pattern in relation to individual subjects, thus women represent an above average 12 per cent of the total in chemical engineering, but under 6 per cent in electrical engineering and electronics, a field generally regarded as having a less traditional heavy engineering image. This rather lower representation may be because the competition for places is much harder in these subjects.

Table 2 Percentage of women in main graduate occupations.

\begin{tabular}{lr} 
Teachers & $56.0 \%$ \\
Medics & $29.6 \%$ \\
Scientists & $16.0 \%$ \\
Accountants & $8.1 \%$ \\
Lawyers & $15.1 \%$ \\
Architects & $4.2 \%$ \\
Engineers & $1.2 \%$ \\
\hline
\end{tabular}

Source: Census of Population, for 1981.

In terms of jobs, the contrasts with men are even more marked. The most fundamental difference in 1981 was that almost a third of the women graduates (about 200,000) were not working or seeking work, mostly presumably for family reasons, while among men the corresponding figure was only 11 per cent. Interestingly, similar proportions of men and women graduates were unemployed three per cent. Of the 450,000 working women, almost half were in teaching and indeed in this occupation they outnumbered their male counterparts. In medicine, women are relatively well represented, accounting for nearly one in three of all medical and dental practitioners. However, only about one in six of scientists are women, and fewer than one in eighty of the engineers (Table 2). There are far more graduate women in accountancy and in law than in engineering.

To remedy this low representation of women in science and engineering, for which both women and society generally suffer, the year 1984 was designated as WISE - Women in Science and Engineering - Year. Sponsored by the Engineering Council and the Equal Opportunities Commission, the main aim of the campaign was to educate and encourage girls, ()1985 Nature Publishing Group through a wide range of promotional activities, to take up careers in science and engineering. Even before WISE Year there have been initiatives aimed at encouraging schoolgirls to consider engineering careers. These have included special "Insight" programmes to allow sixth-formers to have close experience of engineering over a period of a weeks in industry, special scholarships and local school-industry liaison activities. The latter have not always been a success, however, with one girls' school returning a package of engineering careers leaflets with the comment "This must have been sent to us in error, this is a girls' school"'

WISE Year included over 500 special conferences and events in schools, colleges and employers' premises, and many activities are continuing into 1985 and beyond. A limited number of new scholarships for girls was awarded during 1984 by the Engineering Training Board and others, but because the year was primarily aimed at raising awareness, it will be several years before any effective evaluation can be made, when any changes in subject choice among girls in schools and higher education will start to become apparent. At any rate, the organizers are already claiming that the year was a success.

An added urgency for women to enter technology-based courses was the fact that 1982 saw the number of 18 -year-olds in the population, the traditional entry group into higher education, start to fall. The number will decrease from $1,000,000$ to 650,000 in 1995 with most of the fall occurring during the latter part of the period. While the implications of this fall in terms of demand for higher education places have been hotly debated for several years now, in the cases of less popular subjects such as engineering, such a fall could have a significant effect on the numbers graduating. A rising relative demand by women will help mitigate against the overall fall and an increasing representation by women on engineering and technology courses may be the only means of ensuring an adequate future supply of graduates with key skills. Thus meeting the needs of the market and providing equality of opportunity could well become selfsupporting policies in the late 1980s.

Richard Pearson in at the Institute of Manpower Studies, Mantell Building, University of Sussex, Brighton BNI 9RF, UK. 